\title{
Patterns of Metacognitive Skills and External Representation of Students in Chemistry Problem Solving
}

\author{
Ijirana Ijirana ${ }^{1, *}$, Jusman Mansyur \\ Universitas Tadulako-1, Jl. Soekarno Hatta No.KM. 9, Kota Palu, Sulawesi Tengah 94148 \\ ${ }^{1}$ ijiranarizal.untad@gmail.com* \\ *corresponding author
}

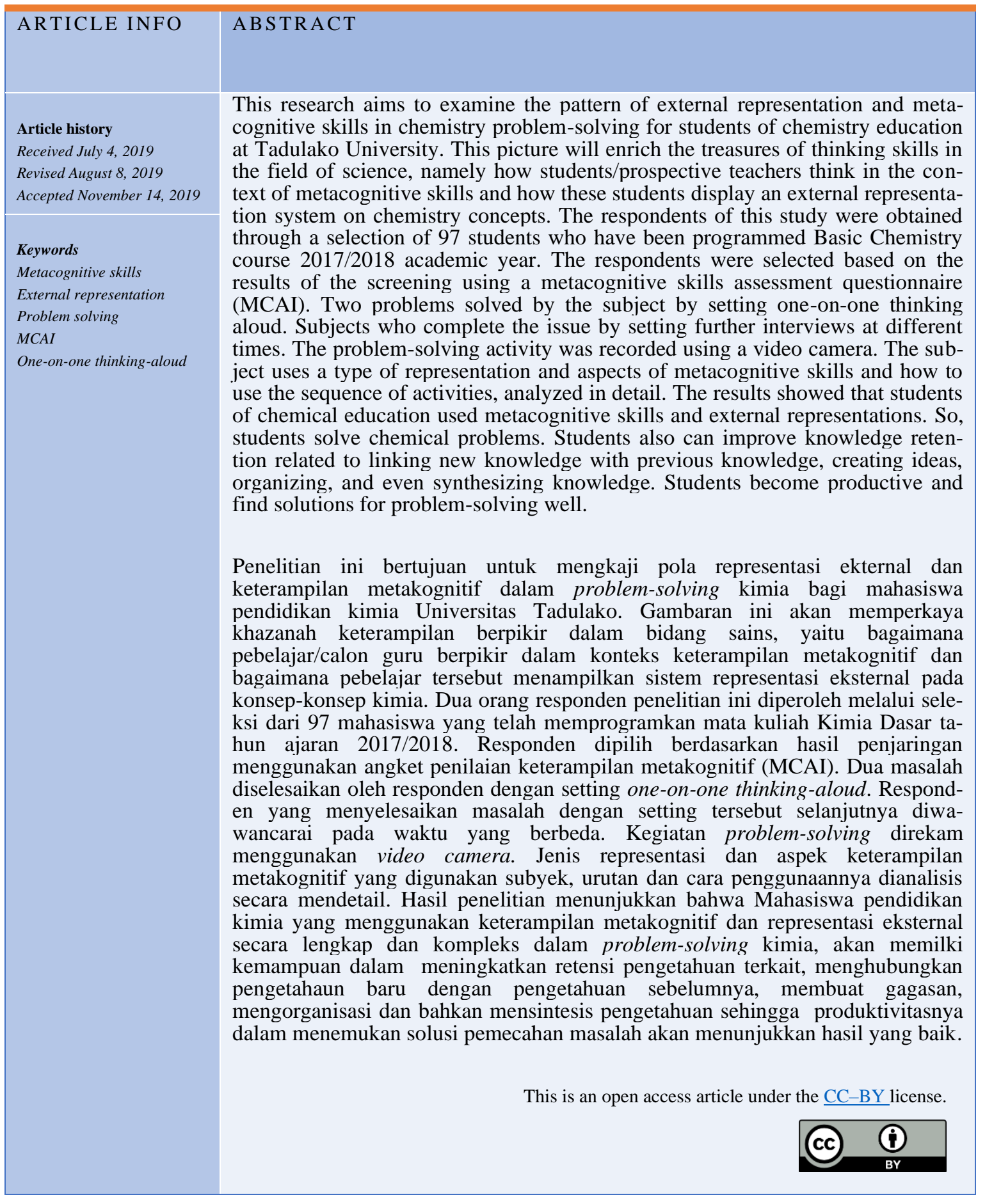




\section{Introduction}

Science education aims to develop competence of thinking and to act rationally (DeBoer, 2000). This competency can be measured by problem-solving. According to (Kirtikar, 2013) someone who has problem-solving skills in addition to having the ability to apply facts, laws, and principles also allows being able to think critically.

According to (Cooper \& Sandi-Urena, 2009), the development of problem-solving abilities in chemistry can be done using metacognitive skills. However, the use of noncognitive skills is incomplete (only using planning skills not using monitoring and evaluation); it will potentially fail in problem-solving (Ijirana \& Supriadi, 2018). Likewise, in physics, (Nurmasyita et al., 2013) also found that a subject pattern can perform complete problemsolving stages and use more time portions of the understanding stage, so it tends to be able to solve problems in a faster time and productivity of general problem-solving. In addition, problem-solving is also influenced by one's ability to represent a problem found. (Ibrahim \& Rebello, 2013) stated that problem-solving in problems with different mental representation formats could be solved by students by arranging mental representation categories.

(Cook, 2006) found representations in learning science not only improves the ability of problem-solving but can also increase the retention of related knowledge and facilitate the integration of new knowledge with prior knowledge. More specifically, the findings of (Cox \& Jones, 2011; Matijašević et al., 2016) focus on the types of external representations in learning basic, organic, and biochemical chemistry. They found that external representations and visual thinking have the potential to make ideas and act. Complex problems are more accessible, organized, and synthesized knowledge. (Cao \& Brizuela, 2016) which focuses on the representation and understanding of physics in the electric field and find that student reasoning is more varied at certain moments and that variability shows productive thought processes in studying the electric field. In learning activities, according to the findings of (Ningsih et al., 2013), physics teachers displayed forms of representation in verbal and algebraic formats, while in presenting concepts, most of the teachers did not emphasize the importance of diagrams.
The use of external representation systems in problem-solving, especially those related to diagrams, (Mansyur, 2015) found that some teachers tended to separate the steps of diagramming from the interpretation and identification of variables so that they did not provide adequate results. (De Cock, 2012) stated that through the format of representation, certain concepts or problems can be expressed or communicated, such as a graph, picture, freebody diagram (FBD), formula, and others. Skill in interpreting and using diverse representations and in coordinating multiple representations (MR) is very valuable as a tool to understand concepts and to facilitate problemsolving.

(Ibrahim \& Rebello, 2013)found that when using a single representation format (only verbal, symbol or graphic) that requires quantitative solving, students think of forms of equations by matching patterns of information than using a qualitative approach in which provides interpretation and deep understanding. Likewise, when interpreting a representation (only graphics or symbols), they tend to focus on superficial attributes rather than extracting physical information to the maximum. It is possible that the ability or inability to engage in the process of connecting and translating information when dealing with multi representations can be influenced by types of cognitive structure and even long-short-term memory (LSTM) (Zhang et al., 2019).

This research is expected to obtain findings of metacognitive skills and external representation patterns in chemistry problem-solving of students in Chemistry Education. Results of the research will enrich the evidence and theory of thinking skills in the field of science, namely how student teachers think in the context of metacognitive skills and how the students display systems of external representation on chemical concepts.

\section{Method}

This research is basic research with qualitative methods. The focus of this research is to investigate metacognitive skills and patterns of external representation in chemical problemsolving for chemistry education students at Tadulako University using Grounded Theory. Descriptions of metacognitive skills and external representation patterns were obtained from students with different metacognitive skills 
based on the results of the selection through a questionnaire developed by (Cooper \& SandiUrena, 2009).

The data collection begins with selecting students enrolled in the chemical education study program at Tadulako University in the academic year 2017/2018 with different cognitive skills. A total of 97 students were given a meta-cognitive skills assessment questionnaire (MCAI). Respondents of this study were two students, i.e Helpina and Wahyuni, (pseudonym). The respondents were taken from several students who rated themselves as non-cognitive skills during problem-solving with a score $>80$. The respondents solved two problems developed by thinking-aloud one-on-one settings. The second problem was solved a week after the first problem was solved. Respondent who solved the problem using the same method were then interviewed at different times. Problem-solving activities with these settings and interviews were recorded using a video camera.

The results of problem-solving and interviews were categorized and coded in two ways. The first category and code for the use of representation. Noting available forms of representation (pictures, symbols, written language (verbal), formula, and mathematical language) (Kohl \& Finkelstein, 2005). The second, encoding for the use of metacognitive skills. This encoding involved the activities of the subject, such as planning, monitoring, and evaluating. Planning includes activities, reading, translating, setting goals, formulating problems, making plans. Monitoring includes problem-solving activities, i.e., reviewing or rereading problems, checking answers, and pausing while looking at the paper or the answer in front of it. Evaluating includes activities that follow the discovery of the correct answer (right or wrong) and involves taking several types of steps to check the correctness of the answer (final or intermediate answers), and or the subject decides directly that the answer is wrong and starts working again. This evaluation also includes reflection, namely whether the answers obtained make sense or are like yes not expected.

\section{Results and Discussion}

In the problem-solving process, students solved chemical bonding problems by exploring their abilities through the construction of external representation and non-cognitive skills.

\section{A. Student's Metacognitive Skills and External Representations: Helpina (S1)}

Problem-solving activities are activities carried out by Helpina, namely: First, trying to understand the problem by reading quickly then slowly when it comes to the formulation of the problem. Problems are read over and over three times and then interpret. The following excerpt from his statement: "First, sulfur binds to oxygen a compound formed from sulfur with three oxygen atoms, meaning there are 3 oxygen bind sulfur. Binding here if compared to everyday life is like a friendship". Second, making a problem statement literally (Fig. 1).

\section{a. Bagaimana caro kedua atom ini beriketan b. Apa bentuk morkulnya.}

Fig. 1.Problem Statements by S1

Third, plan, namely developing a strategy for solving problems. An excerpt from the interview she stated: "The first thing to do is look for the valence electrons from sulfur and oxygen. Valence electrons can be seen from configurations in atomic squares, then make the Lewis structure". The strategy created by S1 will be easier to determine the Lewis structure of the central S atom in the SO3 molecule. Determination of electron configurations on the elements $\mathrm{S}$ and $\mathrm{O}$ will make it easy for $\mathrm{S} 1$ to determine the number of electrons filled in each orbital, especially in the outer shell orbitals. Therefore, S1 said that to do planning skills that begin with understanding, translating, making problem formulations, and problem-solving strategies before solving problems. Fourth, resolve the problem based on the plan that was made. Here are the results of solving the problem (Fig. 2).

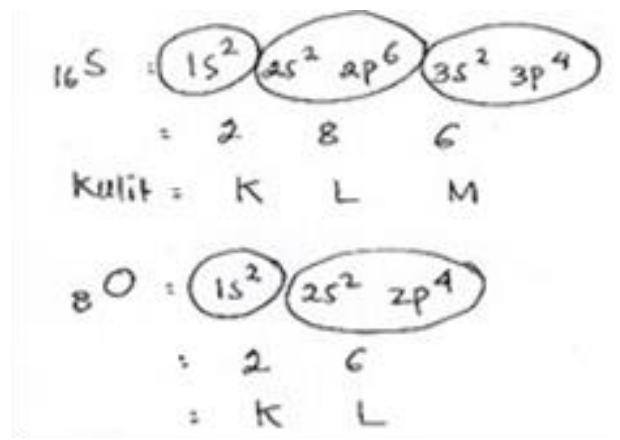

Fig. 2.Electron Configuration by S1 


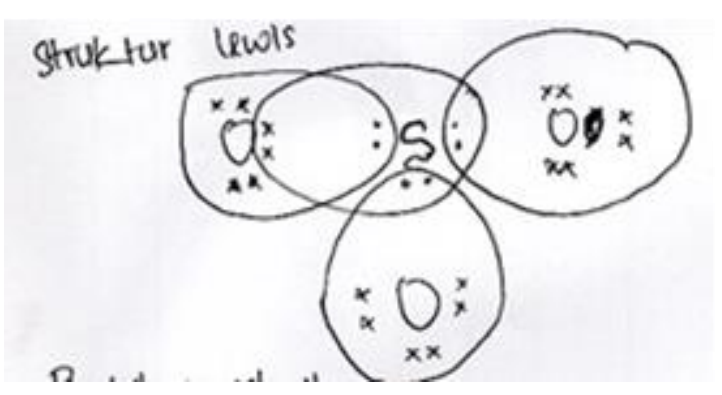

Fig. 3.Lewis Electron Structure

At this stage, S1 solved the problem by writing the sulfur symbol with $S$ and oxygen with O. S1 made a mathematical representation by writing the el-electron configuration to facilitate the arrangement of the number of electrons in each of its orbitals on the atomic shells. This step was carried out to make it easier to create a Lewis structure by specifying the number of points instead of electrons around the atom. It appears that in the sulfur atom, there are six electrons in the outer shell as well as in the oxygen atom. Considering the shape of the molecule made by $\mathrm{S} 1$ by Lewis naturally, this is correct because all the atoms involved have eight valence electrons. S1 described the Lewis structure of all the atoms in SO3 meeting the octet rules and being in a state of resonance. However, the experimental data more support Lewis structure with bonds between sulfur atoms with oxygen atoms is a double bond with 3 $\mathrm{S}-\mathrm{O}$ bonds on $\mathrm{SO} 3$ of the same length, which is $141.8 \mathrm{pm}$.

Fifth, when S1 has solved the problem, she tried to monitor the answer by stating that the ties in $\mathrm{SO} 3$ are covalent coordination bonds. The condition for the formation of coordinating covalent bonds is the existence of free electron pair (PEB). S1 then defined a covalent bond. The following excerpt: "Covalent bonding is the use of electrons together". After that, S1 suddenly stated that, if so, here it is not the coordination covalent bond, but the covalent bond. S1 monitored the results by reviewing in terms of the type of bond, although not sure of the statement in terms of changes in covalent sentences coordinating with covalent. Basically, S1 has been able to monitor the result, but it is not perfect because, in the bond between sulfur and oxygen, there are types of covalent bonds and covalent coordination.

Sixth, from the solution, S1 then checked the correctness of the answer by connecting with the concept of covalent bonding and the conditions for the formation of a cordialcovalent bond. Then S1 analyzed the solution and decided, with the statement that "The requirement for coordinating covalent ties is to have a PEB. PEB is a lone pair of electrons. This compound has no free electron pairs, so this bond is really not a coordinating covalent bond but a covalent bond". The second evaluation was by convincing the truth for decision making. Following is the S1 statement, "This is around $8 \mathrm{~S}$ electrons and $8 \mathrm{O}$ electrons, 8 electrons, so the total number of electrons in each atom in the molecule is $8 " . \mathrm{S} 1$ also evaluated by making another example, namely by supposing the $\mathrm{S}$ atom, which binds to the two $\mathrm{H}$ atoms, then in the molecule, there are 8 outer electrons around $\mathrm{S}$ and two outer electrons around $\mathrm{H}$ (hydrogen).

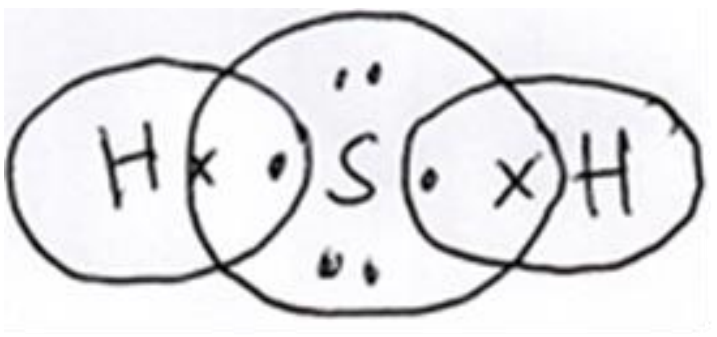

Fig. 4.Lewis $\mathrm{H}_{2} \mathrm{~S}$ Structure

Seventh, S1 reviewed the objectives to be achieved and stated: "One more goal has not yet been reached, namely determining the shape of the molecule."

Eighth, S1 rearranged her plans by stating: "To determine the shape of a molecule, then: 1) let's see the PEB bound electron. 2). This is S as the central atom, which can be denoted by A, and the bound atom is denoted by $\mathrm{X}$, and the free electrons are E".

Ninth, S1 solved the second problem

$$
\begin{aligned}
& \text { Bentuk muikul } \\
& \text { Jurach } P E B=E=0 \\
& P E 1=X=3 \\
& \text { Atomousak }=A \\
& \begin{array}{l}
\text { Mark al yang tribentuk. } \\
\mathrm{AX}_{3}=\text { trigond pronor }
\end{array}
\end{aligned}
$$

Fig. 5. Second Question Solving

Tenth, S1 evaluated and believed so that it takes decisions by stating, "The molecular shape is trigonal planar. The decision was made based on the el-electron domain theory.

Patterns of metacognitive skills and S1 external representation in chemical problemsolving can be summarized, as shown in Fig. $6 \& 7$. 


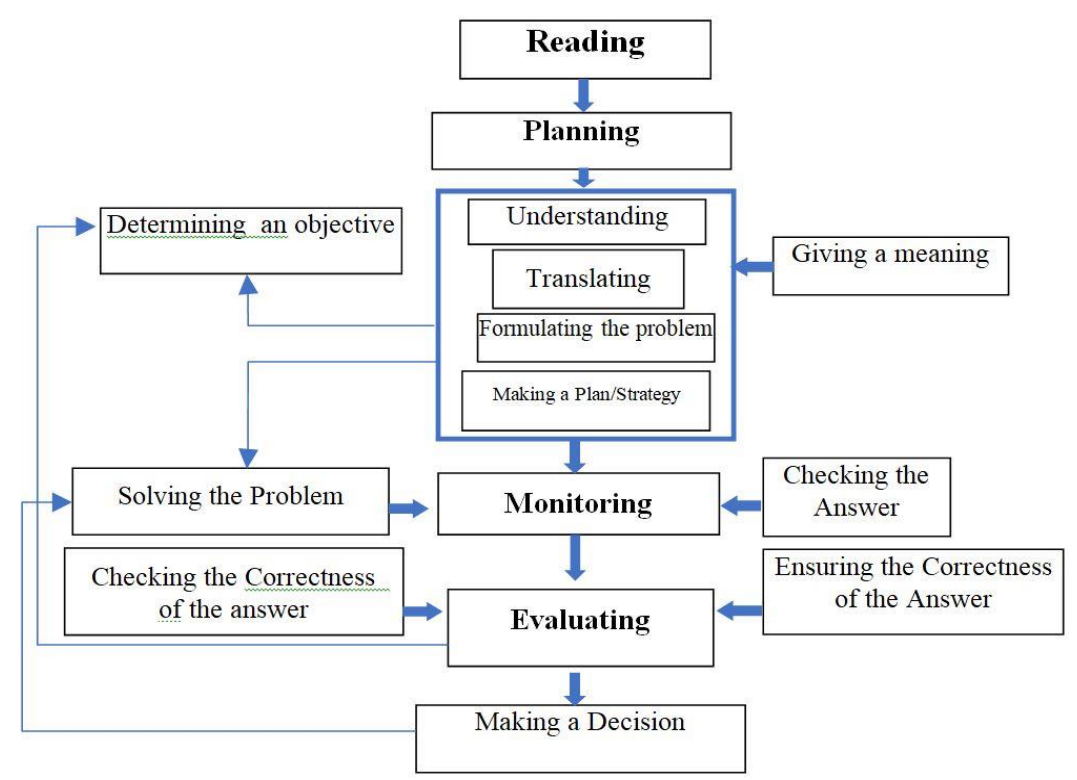

Fig. 6.Pattern of Metacognitive Skills of S1 in Problem-solving

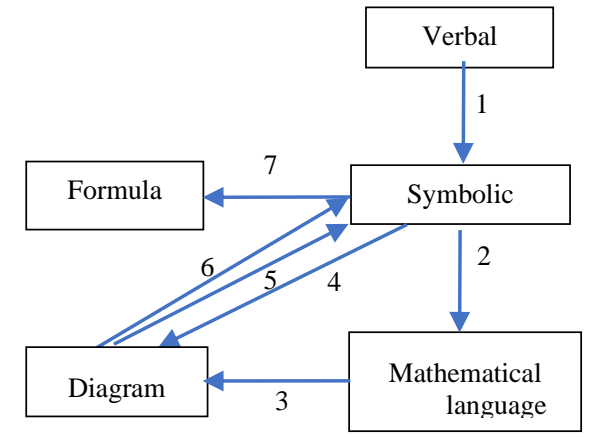

Fig. 7. Pattern of S1 External Representation When Problem-solving

\section{B. Student's Metacognitive Skills and}

External Representations: Wahyuni (S2)

S2 solved the second problem with several stages. First, read and tried out to understand the problem by interpreting the problem in your own words: "Iron has an atomic number 26 and oxygen with an atomic number 8 . While the produced compound is iron (III) oxide or hematite."

Second, expressed the objectives to be achieved after rereading the problem statement. S2 stated that "there are two objectives achieved, namely, 1) Determine the process of the formation of iron that binds with oxygen and 2) determine the formula for its compounds."

Third, made plans by developing strategies for solving problems. S2 stated that "to achieve the goal, what needs to be done is to make configurations of electron $\mathrm{Fe}$ and $\mathrm{O}$, then describe the process of forming bonds that occur between the release and reception of electrons."

Fourth, S2 solved the problem that has been planned and monitors the answer. S2 wrote the symbol of iron with $\mathrm{Fe}$ and oxygen with $\mathrm{O}$ completed with their respective atomic numbers. S2 then made an electron configuration, as in Fig. 8. S2 showed a caution in writing electron configurations by applying the Aufbau principle, which starts by filling the orbitals with the lowest energy.

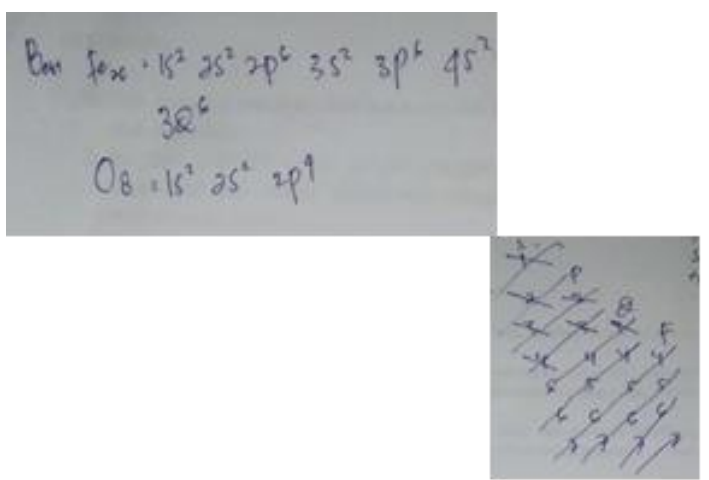

Fig. 8.Fe and O Electron Configuration

In the thinking-aloud session, S2 stated that "Oxygen with an electron configuration of 26 electrons requires 2 electrons to achieve stability. If these two elements bind, then $\mathrm{Fe}$ will release 3 electrons so that $\mathrm{Fe}$ becomes $\mathrm{Fe}+3$, while $\mathrm{O}$ captures 2 electrons to $\mathrm{O}-2$. The load on each element is not equal, so it needs to be equalized". S2 represented the statement in a picture shown in Fig. $9 \& 10$. 


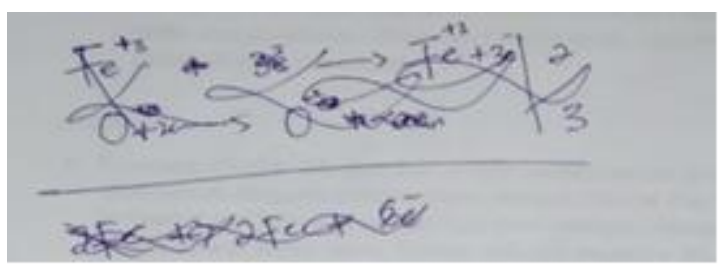

Fig. 9. Bonding Process (1)

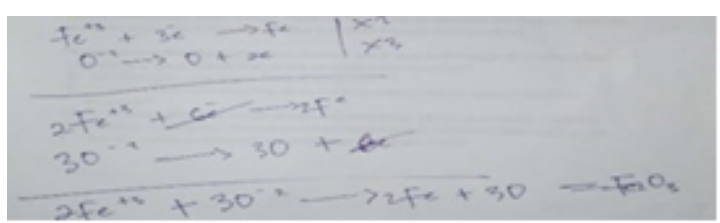

Fig. 10. Bonding Process (2)

It can be seen in Fig. 9 that S2 monitored the results and found that the representation is wrong, so she quickly changed it to Fig.10. Fifth, evaluated the results obtained by interpreting the answers by looking back between the objectives and the results obtained and states "reached its end." The next step taken by $\mathrm{S} 2$ is to check the answers. 1). "I believe my answer is correct because $\mathrm{Fe}$ is oxidized, so it releases 3 electrons. So, $\mathrm{Fe}+3$ is reacted with oxygen -2 charged. So, for the atom to be stable, both must have 6 electrons each released and received". 2) "I believe it is true because if this is tested then the resulting $\mathrm{Fe} 2 \mathrm{O} 3$ molecule is stable, and the total charge is zero (0), so I believe that $\mathrm{Fe} 2 \mathrm{O} 3$ is iron (III) oxide because of $\mathrm{Fe} 2 \mathrm{O} 3$ releases 3 electrons, which means besi (III) oxide".

Wahyuni's pattern of metacognitive skills and external representations of chemical solving problems can be summarized, as shown in Fig. $11 \& 12$, respectively.

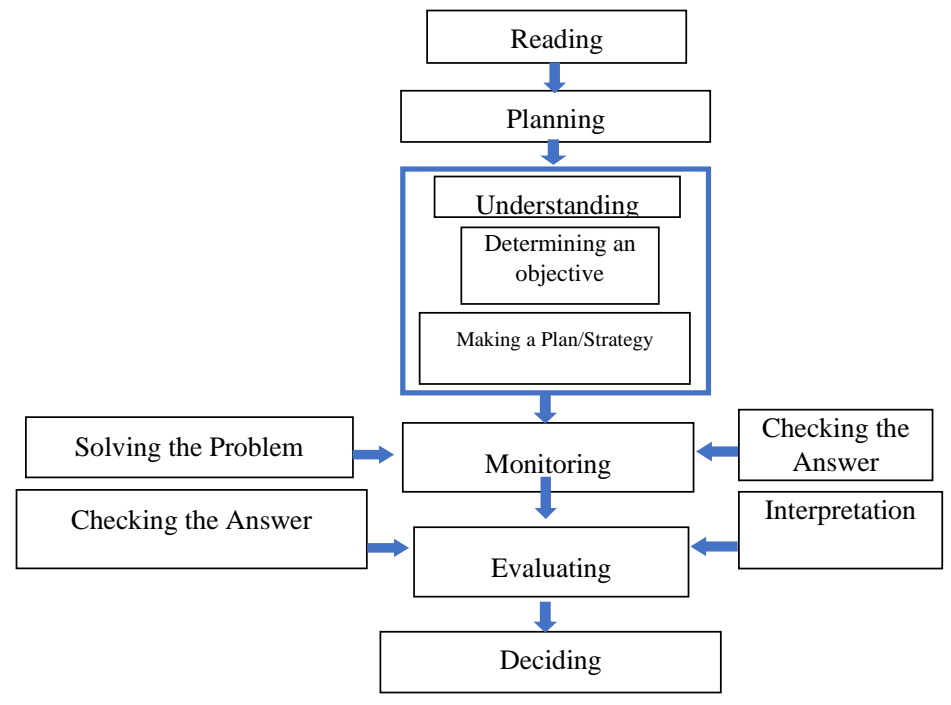

Fig. 11. Patterns of Metacognitive Skills for S2 When Problem-solving

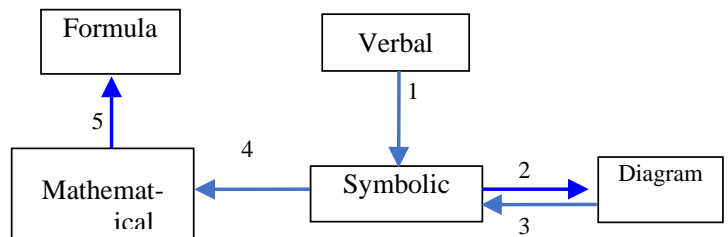

Fig. 12. External Representation Pattern for S2 When Problem-solving

The behavior of $\mathrm{S} 1$ and $\mathrm{S} 2$ in chemical problem-solving shows that they used complete metacognitive skills so that their productivity in finding solutions shows good results. Relevant research has been conducted in the field of physics and also found that a pattern of subjects doing more complete stages of problem- solving, tends to be able to solve problems in a faster time, and productivity of problemsolving is also done very well (Nurmasyita et al., 2013). Therefore, these two findings work together to illustrate that a person will succeed in problem-solving if he/she uses the complete metacognitive skills.

The ability of problem-solving is also determined by how capable a person is using representations during problem-solving. This is also demonstrated by S1 using five types of representations (Fig. 11) to facilitate problemsolving.

Problem-solving shown by $\mathrm{S} 1$ is the ability to associate new knowledge with previous knowledge and be able to create ideas and or- 
ganize information. This shows the development of the findings of representations made by students. Findings that are in line with these findings are representations in learning science not only improve problem-solving abilities, but can also increase the retention of related knowledge and facilitate the integration of new knowledge with prior knowledge (Cook, 2006), build integration of several relevant information and can create HOTS thinking abilities (analyze, apply, and create) in a person (Tajudin \& Chinnappan, 2016). Even findings in chemistry learning are specifically stated that external representations and visual thinking in learning basic, organic, and biochemical chemistry cause a person to be able to make ideas, organize, and synthesize knowledge (Cox \& Jones, 2011). This cognitive scheme can disturb mathematical reasoning in solving chemical-physical problems if students have a limited understanding of the equation (Matijašević et al., 2016). Therefore, someone who does problem-solving by involving metacognitive skills and external representations and understands mathematical equations will increase the retention of related knowledge, be able to connect new knowledge with previous knowledge, make ideas, organize, and even synthesize knowledge. Thus the results of this study can be input for teachers in determining learning strategies that will be used by considering the basis of representation and compound ability of students (Yanti et al., 2018).

\section{Conclusion}

Chemical education students who use complete and complex metacognitive skills and external representations in chemical problemsolving will have the ability to increase the retention of related knowledge, connect new knowledge with prior knowledge, make ideas, organize, and even synthesize knowledge so that productivity can find solutions to future problems will show good results. This research study was conducted to explore students' abilities in the context of metacognitive skills and external representations of students who program basic chemistry courses. To examine the retention of the two characteristics of these students, it is necessary to conduct further cross-sectional research in advanced chemistry courses or different subjects.

\section{References}

Cao, Y., \& Brizuela, B. M. (2016). High school students' representations and understandings of electric fields. Physical Review Physics Education Research, 12(2), 20102.

Cook, M. P. (2006). Visual representations in science education: The influence of prior knowledge and cognitive load theory on instructional design principles. Science Education, 90(6), 1073-1091.

Cooper, M. M., \& Sandi-Urena, S. (2009). Design and validation of an instrument to assess metacognitive skillfulness in chemistry problem solving. Journal of Chemical Education, 86(2), 240.

Cox, J. R., \& Jones, B. W. (2011). External representations in the teaching and learning of introductory chemistry. Creative Education, 2(5), 461-465.

De Cock, M. (2012). Representation use and strategy choice in physics problem solving. Physical Review Special Topics-Physics Education Research, 8(2), 20117.

DeBoer, G. E. (2000). Scientific literacy: Another look at its historical and contemporary meanings and its relationship to science education reform. Journal of Research in Science Teaching: The Official Journal of the National Association for Research in Science Teaching, 37(6), 582-601.

Ibrahim, B., \& Rebello, N. S. (2013). Role of mental representations in problem solving: Students' approaches to nondirected tasks. Physical Review Special Topics-Physics Education Research, 9(2), 20106.

Ijirana, I., \& Supriadi, S. (2018). Metacognitive skill profiles of chemistry education students in solving problem at low ability level. Jurnal Pendidikan IPA Indonesia, 7(2), 239-245.

Kirtikar, R. (2013). A Problem-solving approach for science learning. New Perspectives in Science Education.

Kohl, P. B., \& Finkelstein, N. D. (2005). Student representational competence and selfassessment when solving physics problems. Physical Review Special TopicsPhysics Education Research, 1(1), 10104.

Mansyur, J. (2015). Teachers' and students' preliminary stages in physics problem solving. International Education Studies, $8(9), 1-13$.

Matijašević, I., Korolija, J. N., \& Mandić, L. M. (2016). Translation of $\mathrm{P}=\mathrm{kT}$ into a pictorial external representation by high school seniors. Chemistry Education Research and Practice, 17(4), 656-674. 
Ningsih, H. Y. S. T., Mansyur, J., Kamaluddin, K., \& Darsikin, D. (2013). Perilaku Penggunaan Representasi Eksternal Guru Fisika dalam Aktivitas Pembelajaran. Prosiding Seminar Nasional Pendidikan.

Nurmasyita, N., Mansyur, J., \& Syamsu, S. (2013). Analisi Penggunaan Waktu Siswa dalam Tahap-Tahap Physics Problem Solving. JPFT (Jurnal Pendidikan Fisika Tadulako Online), 6(2), 7-12.

Tajudin, N. A. M., \& Chinnappan, M. (2016). The Link between Higher Order Thinking Skills, Representation and Concepts in
Enhancing TIMSS Tasks. International Journal of Instruction, 9(2), 199-214.

Yanti, Y. R., Amin, S. M., \& Sulaiman, R. (2018). Representation of students in solving simultaneous linear equation problems based on multiple intelligence. Journal of Physics: Conference Series, 947(1), 12038.

Zhang, W., Li, Y., \& Wang, S. (2019). Learning document representation via topicenhanced LSTM model. Knowledge-Based Systems, 174, 194-204. 